\title{
There Is No Magic: Developing Grammar Skills Using Blackboard Quizzes
}

\author{
Carla Buchheit
}

During the summer of 2012 I got tired of Level 1 students begging me for more direction in their effort to move up within the AEC. They seemed to want a magical elixir, and my responses felt like a placebo. I was weary of both. So, it was time to address the issue by beginning a plan that had been simmering for a while. The plan was to create a series of grammar quizzes on Blackboard (Bb).

\section{Project Overview}

The goal for this Bb project was to give Level 1 grammar students (016B and 016C) a venue for self-improvement that 1) presented and reinforced the grammar skills necessary to successfully complete Level 1, and 2) guided students to develop paraphrasing skills.

During the fall semester I began to make what ended up as $\mathrm{Bb}$ quiz pools covering seven grammar topics. These test pools have about 350 items and were presented to students in 10-item quizzes by content area. Questions were pulled randomly from $40+$ item pools, so students saw different items on each quiz they took and they could take as many quizzes as they wanted.

However, before the project even began, I realized that simply making quizzes was an inadequate effort on my part. Students in 016B and 016C would be taking the same quizzes, but these two groups of students do not cover the same grammar material nor in the same depth, and do not move at the same pace. So, I created GrammarPoints as supportive teaching tools for the quizzes.

GrammarPoints (GPs) are PowerPoints that provide an overview of the grammar structures and paraphrasing skills that are used in each quiz topic. This is an example of why GPs are needed. 016C students studied enough/not enough as count/non-count quantifiers, so that concept was included in some quiz items. However, 016B students did not study that quantifier in class. In order to have a chance at being successful on the count/non-count quizzes, they needed some exposure to this language. Thus, GrammarPoints were needed not just to remind students of the grammar content in each quiz, but also to introduce unfamiliar content.

The GPs are not designed to provide depth; they are equal parts overview and review. In Figure 1 there are three GP slides that demonstrate the introduction/review of quantifiers. The 016B students who did not know the word "enough" had to either a) ask about it in class, or b) use the incorrect-item feedback to figure out how to learn more about it. I expected and encouraged students to study and use the third slide, the chart, while taking their quizzes. (In fact, we had already covered this material and students had made an enough/less Venn diagram in class.)

Figure 1. Slide Series about Quantifiers from the Count/Non-Count GrammarPoint
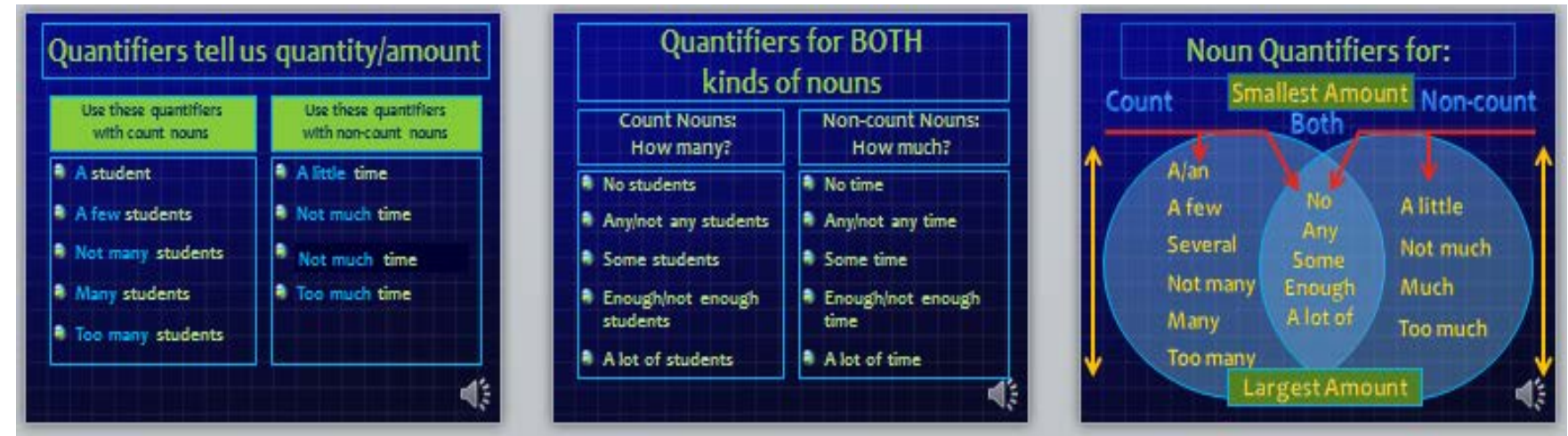

Figure 1. The first slide in this series shows the most commonly used count and non-count noun quantifiers. Each is used with the same common count or non-count noun. The second slide shows quantifiers that can be used with both count and 
non-count nouns and repeats the nouns from the first slide. The third slide is a chart that gives a graphic illustration of the prior two slides. Animation on the slide reminds students that the order is from the smallest to the largest amount.

Just as GrammarPoints were a logical necessity for the quizzes, narration of the slides also became a logical extension. It just was not enough to present this material and expect students to know what it meant; the material needed to be taught. The GPs also needed animation to emphasize specific points and to draw student attention to those points. Figure 2 is a GP slide which demonstrates both the placement of frequency adverbs and how to paraphrase with them. The animation pane at the right on this slide shot organizes and indicates the animation action.

Figure 2. Frequency Adverb Placement and Paraphrasing

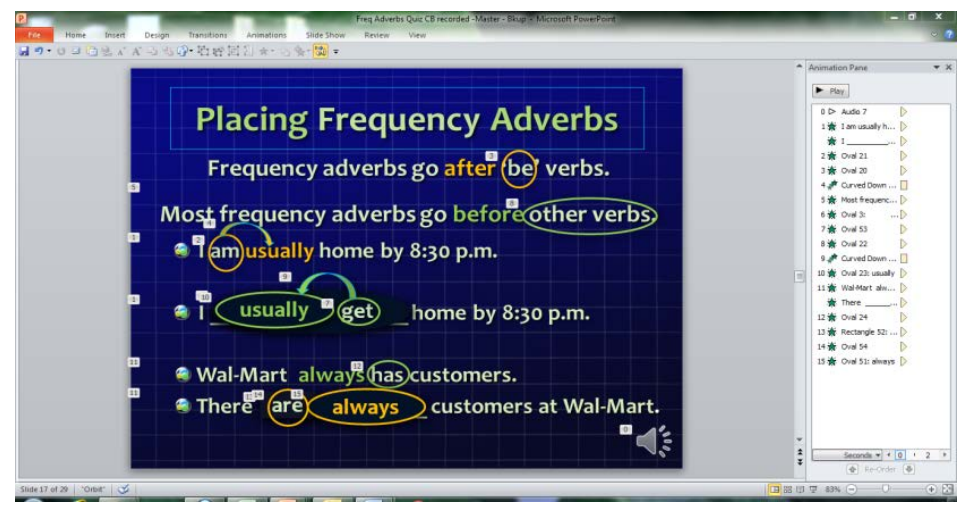

Figure 2. The dual purpose of the quizzes is demonstrated on this slide. First, it provides an example of how to paraphrase by changing the verb. At the same time, it uses color and animation to illustrate the grammar guidelines about frequency adverb placement. The small numbers on the slide indicate the animated action.

From the beginning, I knew that Level 1 students and Blackboard might not be an ideal combination. I had tried administering paraphrase tests on Bb for two semesters before I started this project. I knew that minimal computer/typing skills, poor spelling, and lack of familiarity with Blackboard hinder students. So, I used the GPs to lead students into developing Bb skills. Figure 3 is an example.

Figure 3. Skill Development Slides
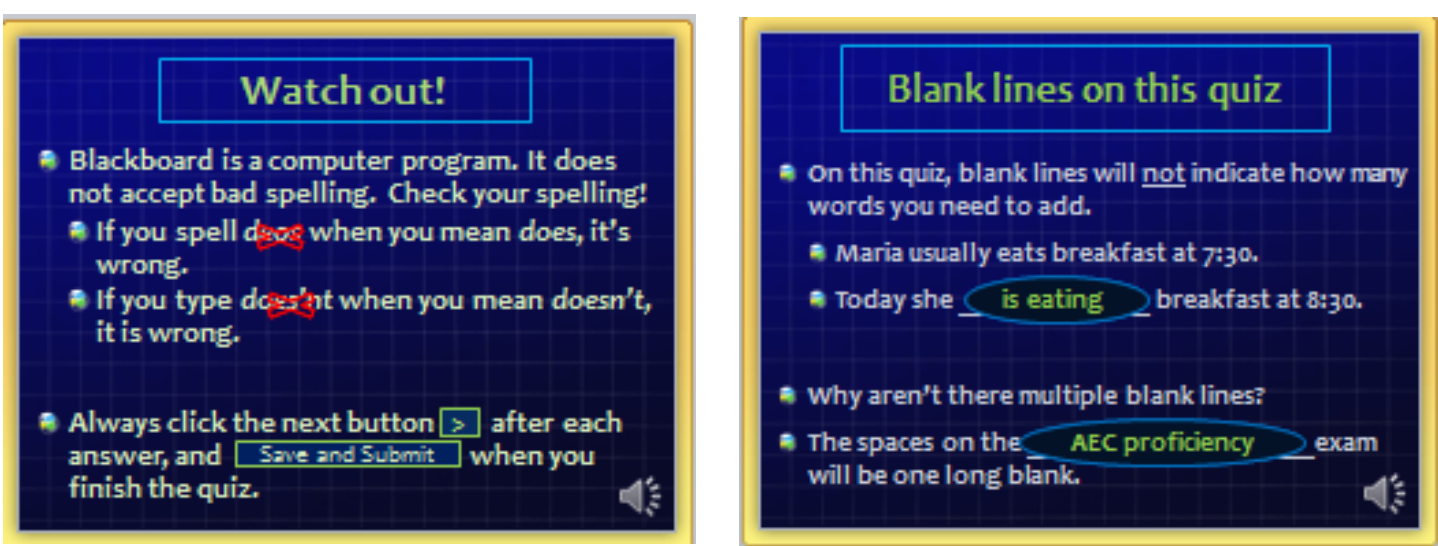

Figure 3. The slide on the left explains to students that Blackboard will not accept misspelled words, and reminds them how to navigate through the quiz and how to finish it. The slide on the right comes from the third quiz pool. It explains the change in the appearance of the blank lines from the prior two quiz pools. 
Additionally, the first two content quizzes used multiple blank lines (Figure 3) to support students' quiz-taking skill development. Students learned that meant that three words were the expected response. Initial GPs were watched and grammar quizzes taken in the LEO lab with assistance available from the LEO staff, the teacher, and the Level 1 student assistants, so we could ease student confusion.

I expected students to watch each GP before they took a new content quiz, and in order to be sure they did this, I used the adaptive release feature of Blackboard. For the first few content quizzes, this feature kept the quizzes hidden until after the GP was viewed. Later, I added passwords to the end of the GP that students needed in order to activate the quiz. Figure 4 is an example.

Figure 4. Ensuring that Students Watch the GrammarPoints

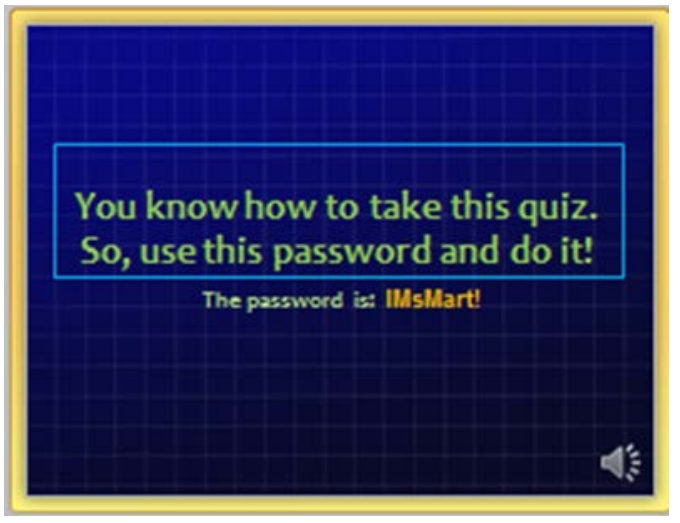

Figure 4. Passwords and adaptive release are two Blackboard options that were used to try to require students to watch the GrammarPoints before taking the first quiz in each topic pool.

During the last week of school, both classes went back to the computer lab to take a 30-minute proficiency-like 40-item test, which was easily (and again randomly) pulled from the already-created content pools, and to take a survey assessing their experience and eliciting their advice for how to improve the project.

\section{The Quizzes}

Since each quiz had 10 randomly picked items, students were assigned to take each quiz at least two times to ensure that they would see a representative sampling. That means that students were required to take 14 quizzes and one review quiz, or 15 quizzes total. In practice, students took as few as 3 and as many as 44 quizzes. Homework credit was given for up to 15 quizzes; scores were not considered. Table 1 shows quiz data.

Table 1

Fall 2012 Blackboard Grammar Quizzes: Student Participation and Scores

\begin{tabular}{lccc}
\hline & 016B & 016C & B \& C \\
\hline Total Number of Students & 15 & 20 & 35 \\
Total Blackboard Quizzes Taken & 368 & 333 & 701 \\
Average Quizzes Taken/Student & 25 & 17 & 20 \\
Average Blackboard Quiz Score/Student & $42.47 \%$ & $55.05 \%$ & $49.94 \%$ \\
\hline
\end{tabular}

I anticipated average scores approaching 80\%; that did not happen. Only three students averaged scores in the $70^{\text {th }}$ percentile. And while all three of those students moved up two or more levels (two to Level 2 Grammar, one to Level 4 
Grammar), there is not a clear relationship for all students. Some students took a few tests, scored well or poorly and made progress. Others took many tests, scored poorly or well, and made little progress. But, the average quiz scores, as shown in Table 2, indicate a possible statistical significance that should be pursued with continued data collection and analysis.

Table 2

Relationship of Post-Proficiency-Exam Placement of 016B/C Students to Blackboard Grammar Quiz Participation and Scores

\begin{tabular}{cccc}
\hline $\begin{array}{c}\text { Post-Proficiency- } \\
\text { ExamPlacement for } \\
\text { 016B/C Students } \\
\text { (Spring 2013) }\end{array}$ & $\begin{array}{c}\# \\
\text { Students }\end{array}$ & $\begin{array}{c}\text { Average } \\
\text { \# Quizzes } \\
\text { Taken }\end{array}$ & $\begin{array}{c}\text { Average } \\
\text { Score on } \\
\text { Blackboard } \\
\text { Quizzes }\end{array}$ \\
\hline ESLP 106 & 1 & 35 & $78 \%$ \\
AEC 036 & 6 & 26 & $59 \%$ \\
AEC 026 & 22 & 19 & $49 \%$ \\
AEC 016 & 6 & 14 & $40 \%$ \\
\hline
\end{tabular}

\section{Survey Results ${ }^{6}$}

At the end of the semester, twenty-five of the thirty-five students participated in a survey about the project. Overall, the survey indicates that students believed that they improved their grammar and paraphrasing skills by studying with the GrammarPoints and taking the quizzes. Furthermore, they felt prepared with paraphrasing strategies to succeed on the proficiency exam. They were likewise positive about the actual GrammarPoints, including the narration and animation. Since research shows that students are not typically good judges of the effectiveness of PowerPoints ${ }^{7}$ (especially as teaching tools), the students' evaluation of the GPs have to be viewed with some reservation.

The survey results reinforced (48\%) one recurring complaint from students throughout the semester: they wanted answers to the quiz items. They always got feedback with each incorrect answer, but they didn't get the correct or possible answers. That they did not was a huge frustration for the students and I could not decide how or when to resolve it.

\section{The Biggest Dilemma: Quiz Answers}

In the survey, $56 \%$ of the students said they would prefer to take paraphrase tests on paper. I can see why: It is much easier. It is easier to look up unfamiliar vocabulary, easier to form study groups, easier to get and share answers—not just from other students but also from the teacher or student assistants or any willing body with some English fluency. There is no time clock ticking, no need to learn Blackboard's eccentricities, and misspellings pose no problem. It is also far easier for the teacher to create and implement paper-based tests. But, I had already tried that, both in the classroom and in meetings with interested students outside the classroom and it was not satisfying. Ultimately, students were more interested in getting the answers than in learning how to arrive at the answers.

Lao Tzu, a Chinese philosopher from about the $5^{\text {th }}$ Century, is credited with the saying, "Give a man a fish, feed him for a day. Teach a man to fish, feed him for a life.” Using this as a loose philosophy, my goal with this project was to deliberately not give the answers to the quizzes. Instead, it was to teach them how to think, what to notice, how to apply grammar points and how to find answers by themselves; I wanted students to earn and own their success. Was my adherence to a philosophy worth their heavy frustration? I honestly do not know. Nor do I know at what point I should have provided the answers. Blackboard has limits and I cannot selectively provide answers. That is, I cannot give

\footnotetext{
${ }^{6}$ Survey results can be viewed at: http://www.surveymonkey.com/analyze/?survey_id=36413421\&OPT=NEW

${ }^{7}$ Frey, B., \& Birnbaum, D. J. (2002). Learners' perceptions of the value of PowerPoint in lectures. ERIC Document Reproduction Service: ED467192
} 
answers to students who have taken the quizzes a number of times and not also give the answers to those who have not taken the quizzes at all. Thus, at what point should I have provided answers; after every student took each quiz twicewhich never happened? Two weeks after the quiz opens? Three weeks? How does motivation continue once students know that they will ultimately be given the answers? Would those students who took the quizzes more than 40 times have done so if they knew that they would be given the answers at some point? Would the students who only took three quizzes have been motivated to take more of them ${ }^{8}$ ? I have no answers to these questions.

\section{Encouraging Trends}

Student scores from the Fall 2012 proficiency exam are encouraging. The scores, in Appendix I and Appendix II seem to suggest that, even without being given any answers, these Level 1 students have learned new skills that they were able to apply on the proficiency exam, and, in the process, they successfully became self-learners. To find quiz answers, students reported taking the quizzes multiple times (76\%) and using these tools: their textbooks (64\%), the Internet (48\%), other students (40\%), and a thesaurus (20\%). Thus, these students appear to have maintained motivation in the face of serious frustration (48\% report frustration) and persevered through that frustration. I grew up in a fishing family, so I know that perseverance is a critical fishing skill. If my goal was to teach these students how to fish, i.e. how to persist in the search for an elusive but obtainable goal, then I believe these students successfully met that goal.

\section{Future Research}

Much progress was made on this project this semester, but there is still more to do. One or two more quizzes should be made, feedback on all the items must be improved, 40+-item test pools need dividing into smaller ones, unanticipated correct answers need to be added in the quiz pools, confusing items need to be changed/eliminated, etc. Even I find my GrammarPoint narration boring and too fast, so all the narratives ought to be redone. Fortunately, KU's IT department has complementary software and a small recording studio that might make this task easier. In addition, the same data needs to be gathered over multiple semesters in order to determine whether the student score improvements, documented in Appendix I and II, were due to highly motivated students, these quizzes, a combination of the two, or something else. Finally, when this project was first conceived, the idea was to expand it to the other grammar levels. The student survey, the gathered data, and the tested implementation of the project are meant to provide a basis for determining the value of such an expansion.

\section{Conclusion}

I am optimistic that the investment of time and effort in this project is worthwhile. From the student surveys, we know that students believed that this project helped them to gain grammar, paraphrasing and Blackboard skills. From a comparison of student entry and exit scores on the fall proficiency exams ${ }^{9}$, we know that both student paraphrase and essay grammar scores support those beliefs. And, finally, from the number of non-graded quizzes students took in excess of the number required, we know that many students were self-motivated to learn with this project. Some students (Spring 2013) who are now studying grammar in Levels 2 and 3 are requesting to practice with these quizzes again. Students asking to take quizzes? That's certainly an elixir for me and more research will reveal if might also be a reasonable elixir for our students.

\footnotetext{
${ }^{8} 8 \%$ of students reported not even trying to find the answers.

${ }^{9}$ AEC proficiency exams do not test or measure Bb skills. However, those skills can be assessed by students' demonstrated competency in taking the Bb quizzes.
} 


\section{Appendix I}

\begin{tabular}{|c|c|c|c|c|c|c|c|}
\hline & $\begin{array}{c}\text { Total \# of } \\
\text { students in } \\
\text { class }\end{array}$ & $\begin{array}{c}\text { Students } \\
\text { progressing } \\
\text { to 016C }\end{array}$ & $\begin{array}{c}\text { Students } \\
\text { progressing } \\
\text { to 026 }\end{array}$ & $\begin{array}{c}\text { Students } \\
\text { progressing } \\
\text { to 036 }\end{array}$ & $\begin{array}{c}\text { Students } \\
\text { progressing } \\
\text { to 106 }\end{array}$ & $\begin{array}{c}\text { Students making } \\
\text { progress }\end{array}$ & $\begin{array}{c}\text { Students failing } \\
\text { to make } \\
\text { progress }\end{array}$ \\
\hline 016B & 15 & 1 & 9 & 3 & & 13 & 2 \\
\hline 016C & 20 & & 13 & 3 & 1 & 17 & 3 \\
\hline Total & $\mathbf{3 5}$ & $\mathbf{1} / \mathbf{3 \%}$ & $\mathbf{2 2 / 6 3 \%}$ & $\mathbf{6} / \mathbf{1 7 \%}$ & $\mathbf{1} / \mathbf{3 \%}$ & $\mathbf{3 0 / 8 6 \%}$ & $\mathbf{5 / 1 4 \%}$ \\
\hline
\end{tabular}

\section{Appendix II}

\begin{tabular}{|c|c|c|c|c|c|c|c|c|c|c|c|c|c|}
\hline \multicolumn{2}{|c|}{$\begin{array}{l}\text { Comparison of Fall } 2012 \text { and Prior } \\
\text { Three Semesters for Level } 1 \text { B \& C }\end{array}$} & & & & & & & & & & & & \\
\hline \multirow{4}{*}{$\begin{array}{c}\text { 016B Fall 2012: } \\
15 \mathrm{Ss}\end{array}$} & 016B: Avg Score \& Chg & 8.2 & 38.2 & 30.0 & 23.1 & 45.8 & 22.7 & 31.3 & 84.0 & 52.7 & 141.7 & 265.9 & 124.1 \\
\hline & \% of Discipline Chg & $26 \%$ & $45 \%$ & $57 \%$ & $74 \%$ & $55 \%$ & $43 \%$ & $100 \%$ & $100 \%$ & $100 \%$ & $100 \%$ & $100 \%$ & $100 \%$ \\
\hline & $\%$ of Exam Score Total & $6 \%$ & $14 \%$ & $24 \%$ & $16 \%$ & $17 \%$ & $18 \%$ & $22 \%$ & $32 \%$ & $42 \%$ & & & $47 \%$ \\
\hline & Median Scores & 6 & 42 & 32 & 20 & 45 & 19 & 26 & 85 & 54 & 141 & 268 & 131 \\
\hline \multirow{4}{*}{$\begin{array}{c}\text { 016B Prior } \\
\text { Semesters: F11, } \\
\text { Sp12, Su12: } 27 \\
\text { Ss }\end{array}$} & 016B: Avg Score \&Chg & 9.3 & 22.1 & 12.7 & 17.6 & 37.1 & 19.5 & 26.9 & 59.3 & 32.3 & 132.0 & 208.7 & 76.7 \\
\hline & \% of Discipline Chg & $35 \%$ & $37 \%$ & $39 \%$ & $65 \%$ & $63 \%$ & $60 \%$ & $20 \%$ & $28 \%$ & $100 \%$ & $100 \%$ & $100 \%$ & $100 \%$ \\
\hline & $\%$ of Exam Score Total & $7 \%$ & $11 \%$ & $17 \%$ & $13 \%$ & $18 \%$ & $25 \%$ & $20 \%$ & $28 \%$ & $42 \%$ & & & $37 \%$ \\
\hline & Median Scores & 9 & 26 & 13 & 15 & 40 & 18 & 26 & 60 & 31 & 135 & 223 & 87 \\
\hline \multirow{4}{*}{$\begin{array}{l}\text { 016C Fall 2012: } \\
20 \mathrm{Ss}\end{array}$} & 016C: Avg Score \& Chg & 17.2 & 42.5 & 25.3 & 36.7 & 48.6 & 11.9 & 53.9 & 91.0 & 37.1 & 194.9 & 275.0 & 80.1 \\
\hline & \% of Discipline Chg & $32 \%$ & $47 \%$ & $68 \%$ & $68 \%$ & $53 \%$ & $32 \%$ & $100 \%$ & $100 \%$ & $100 \%$ & $100 \%$ & $100 \%$ & $100 \%$ \\
\hline & $\%$ of Exam Score Total & $9 \%$ & $15 \%$ & $32 \%$ & $19 \%$ & $18 \%$ & $15 \%$ & $28 \%$ & $33 \%$ & $46 \%$ & & & $29 \%$ \\
\hline & Median Scores & 18 & 40 & 21 & 38 & 48 & 10 & 56 & 88 & 29 & 195 & 271 & 78 \\
\hline \multirow{4}{*}{$\begin{array}{c}\text { 016C Prior } \\
\text { Semesters: F11, } \\
\text { Sp12, Su12: } 36 \\
\text { Ss }\end{array}$} & 016C: AvgScore \& Chg & 21.3 & 36.1 & 14.9 & 38.6 & 49.5 & 10.9 & 59.9 & 85.4 & 25.6 & 196.8 & 270.0 & 73.2 \\
\hline & $\%$ of Discipline Chg & $35 \%$ & $42 \%$ & $58 \%$ & $65 \%$ & $58 \%$ & $43 \%$ & $30 \%$ & $32 \%$ & $100 \%$ & $100 \%$ & $100 \%$ & $100 \%$ \\
\hline & $\%$ of Exam Score Total & $11 \%$ & $13 \%$ & $20 \%$ & $20 \%$ & $18 \%$ & $15 \%$ & $30 \%$ & $32 \%$ & $35 \%$ & & & $27 \%$ \\
\hline & Median Scores & 21 & 41 & 19 & 41 & 49 & 7 & 55 & 89 & 25 & 194 & 276 & 76 \\
\hline
\end{tabular}

Back to Table of Contents 